\title{
Fe modified mesoporous hollow carbon spheres for selective oxidation of ethylbenzene
}

\author{
Juan $\mathrm{Du}^{1}$, Lili Zhang ${ }^{1}$, Yixin Zhang ${ }^{1}$, Yifeng $\mathrm{Yu}^{1}$, Yongjun $\mathrm{Gao}^{2^{*}}$ and Aibing $\mathrm{Chen}^{1^{*}}$
}

\begin{abstract}
Fe modified hollow carbon spheres with large cavity and mesoporous shell (Fe-MHCs) were successfully synthesized by a simple pyrolysis and simultaneous deposition method. The organic molecules gases (carbon species) from pyrolysis of polystyrene deposited in the hard template at the catalysis of Fe species existing in the sample during calcination at high temperature. The obtained Fe-MHCs showed uniform spherical morphology with large surface area $\left(924 \mathrm{~m}^{2} \mathrm{~g}^{-1}\right)$, mesoporous structure and a certain amount of Fe loaded. The Fe species and the special structure endowed the materials excellent catalytic activity in the oxidation of ethylbenzene to acetophenone. The conversion of $94.5 \%$ and the high selectivity to targeted product $(97.4 \%)$ could be achieved and the acceptable recycling stability was also exhibited.
\end{abstract}

Keywords: hollow carbon sphere, Fe modified, catalytic, ethylbenzene oxidation

\section{INTRODUCTION}

Mesoporous hollow carbon spheres (MHCs) have attracted increasing attention due to their low density, high surface-to-volume ratios, hollow interior structures and mesoporous textures $[1,2]$. Compared with conventional mesoporous carbon or active carbon materials, the large internal volume of MHCs can provide a storage space that can serve many functions $[3,4]$. Furthermore, the hollow nanostructures with mesoporous shells could facilitate the fast diffusion of reactants and products due to the short diffusion pathway, larger pore, cavity volume, and spherical morphology [5-7]. Templating including hard and soft template method has been widely used to synthesize MHCs [8-11]. Generally, the morphology and the monodispersity of the as-prepared hollow products by soft template method are less satisfactory than that by hard template due to the polydispersity and dynamics [12]. Hence, the method based on hard template has been commonly employed to prepare MHCs due to the better control of morphology, mesoporous structure and monodispersity. Generally, the crucial process is assembling carbon precursors into hard template by infiltration or polymerization. However, the solvent (e.g., water, ethanol or other organics) is necessary, leading to pollutions and increasing the difficulties for recycle and scaleup production. The chemical vapor deposition (CVD) method is a common hard-templating method using organic small molecule gas (e.g., pyrrole, methane and ethylene) as carbon precursor, which can avoid the impregnation of carbon precursor. However, the high technology in general CVD equipment and accurate control in the flow rate of feed gas limit its extensiveness [13].

One of the most critical issues in the development of MHCs is to select suitable low-cost carbon precursor [1418]. Some polymers (e.g., resol, pitch, polyaniline, polyacrylonitrile) can act as carbon precursor due to their commercial availability [12]. Polystyrene (PS), a typical polymer, has been widely used in packaging and is a major source of 'white pollution' [19]. Nevertheless, PS almost has no carbon residue when directly pyrolysis and was more often used as sacrifice hard template for hollow spheres because it is easy to decompose [20]. Therefore, converting PS into functional carbon materials will provide a possible solution for reusing of polymer waste (e.g., polyethylene, polypropylene) and reducing 'white pollution'. Some methods (e.g., crosslink) have used PS as carbon precursor for carbon materials [21,22]. In our previous work, we have also fabricated controllable hollow carbon spheres by the 'dissolution-capture' method using PS as carbon sources [22]. But those methods have some inevitable limitations, such as the tedious procedure, the use of organic solvent, uncontrollable morphology and the difficulty for scale up. Thus, it is

\footnotetext{
${ }^{1}$ College of Chemical and Pharmaceutical Engineering, Hebei University of Science and Technology, Shijiazhuang 050018, China

${ }^{2}$ College of Chemistry and Environmental Science, Hebei University, Baoding 071002, China

* Corresponding authors: (emails: chen_ab@163.com (A Chen); yjgao@hbu.edu.cn (Y Gao))
} 
significant to expand the utilization of PS as carbon precursor with simple process to prepare carbon materials. In addition, the introduction of iron-based catalyst improved the graphitization degree and pore volume. Moreover, graphitic carbon with a porous structure can provide low-resistant pathways and short ion diffusion channels in chemical reaction.

In this work, the Fe modified MHCs (Fe-MHCs) were fabricated via a facile strategy, pyrolysis and simultaneous deposition. The strategy employed Fe modified monodisperse solid silica core and mesoporous shell silica $\left(\mathrm{SiO}_{2} @ \mathrm{Fe}-\mathrm{mSiO}_{2}\right)$ and PS as hard template and carbon precursor, respectively. In the process of pyrolysis and simultaneous deposition, the organic molecules gases (carbon species) deposited on the hard template at the catalysis of $\mathrm{Fe}$ species, existing in the sample, during calcination at high temperature. The hard template and the carbon precursor were mixed without solvent and the impregnation of carbon precursors. The obtained $\mathrm{Fe}$ MHCs features hollow mesoporous structure, high specific surface area and Fe species, ensuring a high performance in the selective oxidation of ethylbenzene reaction.

\section{EXPERIMENTAL SECTION}

\section{Synthesis of Fe-MHCs}

Monodisperse spherical solid core silica particles were synthesized based on the previous work [22]. Typically, $40 \mathrm{~mL}$ of aqueous ammonia $\left(\mathrm{NH}_{4} \mathrm{OH}, 28\right.$ wt.\%) was mixed with a solution containing $1000 \mathrm{~mL}$ of absolute ethanol (EtOH) and $80 \mathrm{~mL}$ of deionized water $\left(\mathrm{H}_{2} \mathrm{O}\right)$. After stirring for $30 \mathrm{~min}, 60 \mathrm{~mL}$ of tetraethylorthosilicate (TEOS, 98\%, Aldrich) was added to the solution and stirred for $6 \mathrm{~h}$ at room temperature. $200 \mathrm{~mL}$ of the above prepared suspension was diluted with $400 \mathrm{~mL}$ of $\mathrm{H}_{2} \mathrm{O}$, and $60 \mathrm{~mL}$ of cetyl trimethylammonium bromide (CTAB) surfactant solution $\left(110 \mathrm{mmol} \mathrm{L}^{-1}\right.$, dissolved in a 2:1 mixture of $\mathrm{H}_{2} \mathrm{O}$ and $\mathrm{EtOH}$ ) was quickly added under vigorous stirring. After stirring for $30 \mathrm{~min}, 4.3 \mathrm{~mL}$ of TEOS was added to the reaction mixture and subsequently stirred at ambient temperature overnight. The assynthesized silica particle suspension was centrifuged and dried at $70^{\circ} \mathrm{C}$ overnight. The obtained dry composite powder was further calcined at $550^{\circ} \mathrm{C}$ for $6 \mathrm{~h}$ in air in order to remove CTAB selectively from the composites. The calcined silica particles were designated as $\mathrm{SiO}_{2} @$ $\mathrm{mSiO}_{2} .10$ wt. $\% \mathrm{Fe}\left(\mathrm{NO}_{3}\right)_{3} \cdot 9 \mathrm{H}_{2} \mathrm{O}$ was impregnated into mesopores of $\mathrm{SiO}_{2} @ \mathrm{mSiO}_{2}$ using ethanol as solvent. After calcined in air at $250^{\circ} \mathrm{C}, \mathrm{SiO}_{2} @ \mathrm{Fe}-\mathrm{mSiO}_{2}$ template was obtained.
$\mathrm{SiO}_{2} @ \mathrm{Fe}-\mathrm{mSiO}_{2}$ template and powder of polystyrene were mixed and placed in quartz boat loaded inside the quartz tube. $\mathrm{N}_{2}$ was introduced as protective and carrier gas. Then the furnace was heated to $800^{\circ} \mathrm{C}$ at a rate of $5^{\circ} \mathrm{C} \mathrm{min}^{-1}$ and kept at that temperature for $3 \mathrm{~h}$ to obtain $\mathrm{Fe} /$ silica/carbon composite. After removing silica by 10 wt. $\% \mathrm{NaOH}$ aqueous solution, the Fe-MHCs was obtained.

\section{Characterization}

X-ray diffraction (XRD) patterns were achieved using a Rigaku D/MAX-2500 system with Cu-Ka $(\lambda=1.5406 \AA$ ). Nitrogen adsorption-desorption isotherms were carried out on a Micromeritics TriStar 3020 instrument at $-196^{\circ} \mathrm{C}$. The Brunauer-Emmett-Teller (BET) method was employed to calculate the specific surface area (SSA), while the Barrett-Joyner-Halenda (BJH) method was applied to analyze the pore size distribution using the desorption branch of isotherm. The total pore volume was obtained from the amount of $\mathrm{N}_{2}$ adsorbed at the relative pressure $\left(P / P_{0}=0.97\right)$. Thermogravimetric analysis (TGA) (Pyris 1 TGA) was performed under air flow from 20 to $800^{\circ} \mathrm{C}$ at a heating rate of $10^{\circ} \mathrm{C} \mathrm{min}^{-1}$.

\section{Catalytic reaction}

For the catalytic oxidation of ethylbenzene, $10 \mathrm{mg}$ catalyst, $1 \mathrm{mmol}$ ethylbenzene and $3 \mathrm{mmol}$ tert-butyl hydroperoxide were dispersed in $3 \mathrm{~mL} \mathrm{H}_{2} \mathrm{O}$ in a $50 \mathrm{~mL}$ sealed glass vessel with magnetic stirring. After reaction at $100^{\circ} \mathrm{C}$ for $24 \mathrm{~h}, 50 \mu \mathrm{L}$ dodecane was added into the tube as the internal standard and $10 \mathrm{~mL}$ ethyl acetate was used as extraction liquid, respectively. Upon the removal of catalyst, the mixture was analyzed by an Agilent GC 7820A equipped with a HP-5 column and a flame ionization detector.

\section{RESULTS AND DISCUSSION}

As illustrated in Fig. 1, this method utilized the $\mathrm{SiO}_{2} @ \mathrm{Fe}-$ $\mathrm{mSiO}_{2}$ as the suitable hard template to provide active sites for pyrolysis simultaneous deposition of PS. Firstly, $\mathrm{SiO}_{2} @ \mathrm{mSiO}_{2}$ was produced by adopting silica nanoparticles as the core and the structure-directing agent for the mesoporous silica shell [23]. Subsequently, $\mathrm{Fe}\left(\mathrm{NO}_{3}\right)_{3} \cdot 9 \mathrm{H}_{2} \mathrm{O}$ was impregnated in the mesopores of the $\mathrm{SiO}_{2} @ \mathrm{mSiO}_{2}$. After calcination in the air, the $\mathrm{SiO}_{2} @ \mathrm{Fe}-$ $\mathrm{mSiO}_{2}$ template was obtained. This template and PS were mixed for pyrolysis simultaneous deposition under $\mathrm{N}_{2}$ protection. The small organic molecules gases (carbon precursor) from pyrolysis of PS can simultaneously deposit on the hard template due to Fe species as catalyst at 


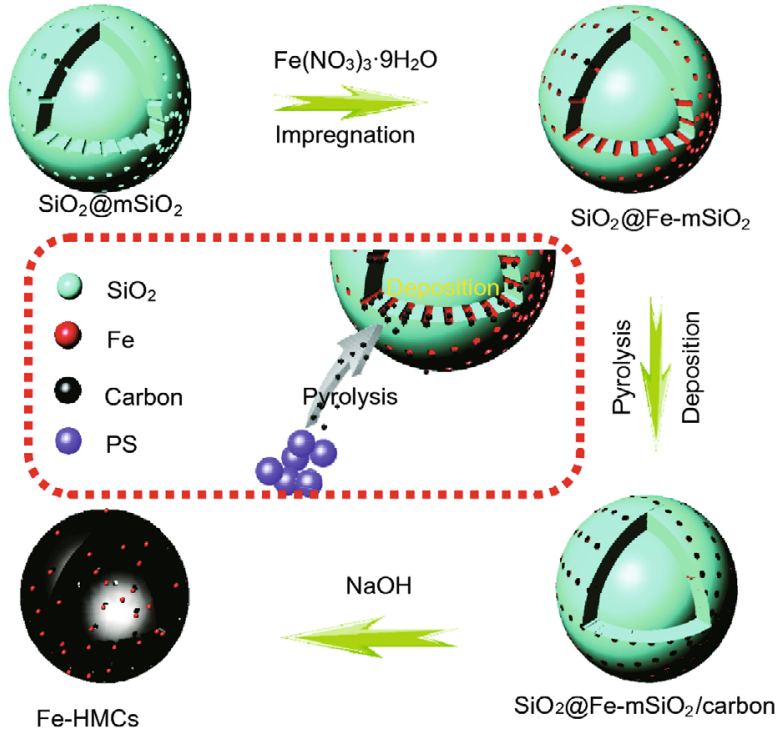

Figure 1 Schematics of the synthesis of the Fe-MHCs.

high temperature, and the mesoporous structure on the shell also provides a space for deposition of carbon precursor. After removal of the silica with $\mathrm{NaOH}$ aqueous solution, the uniform Fe-MHCs were obtained. It was noticed that there was no carbon residue when only $\mathrm{SiO}_{2} @ \mathrm{mSiO}_{2}$ or $\mathrm{Fe}\left(\mathrm{NO}_{3}\right)_{3} \cdot 9 \mathrm{H}_{2} \mathrm{O}$ treated by calcination with PS to pyrolysis simultaneous deposition, indicating the Fe species and porous structure were essential for the deposition of organic molecules gases (carbon species) from pyrolysis of PS. It represented an environment friendly method due to reusing of PS, reducing 'white pollution' and avoiding CVD equipment with high technology or complex operation.

The uniform core-shell structure of $\mathrm{SiO}_{2} @ \mathrm{Fe}-\mathrm{mSiO}_{2}$ could be clearly seen in the transmission electron microscopy (TEM) image in Fig. 2a. The size of $\mathrm{SiO}_{2} @ \mathrm{Fe}-$ $\mathrm{mSiO}_{2}$ was about $200 \mathrm{~nm}$ and the size of silica core and thickness of the mesoporous $\mathrm{SiO}_{2}$ shell was 150 and $25 \mathrm{~nm}$, respectively (the yellow dotted circles in Fig. 2a). From the higher resolution TEM image (Fig. 2b), it was clearly that the mesopores in the shell of $\mathrm{SiO}_{2} @ \mathrm{Fe}-\mathrm{mSiO}_{2}$ were developed generally in a uniform and orderly fashion (the yellow dotted circle in Fig. 2a). There was no obvious Fe nanoparticles observed from the template, indicating the Fe species has been highly dispersed in the pores of $\mathrm{SiO}_{2} @ \mathrm{mSiO}_{2}$. The wide angle XRD pattern further confirmed the highly dispersion of Fe species (in Fig. $3 a$ ). The patterns showed only a wide peak at $23^{\circ}$, ascribed to amorphous silica, and no obvious diffraction peaks owing to Fe species could be found, confirming the

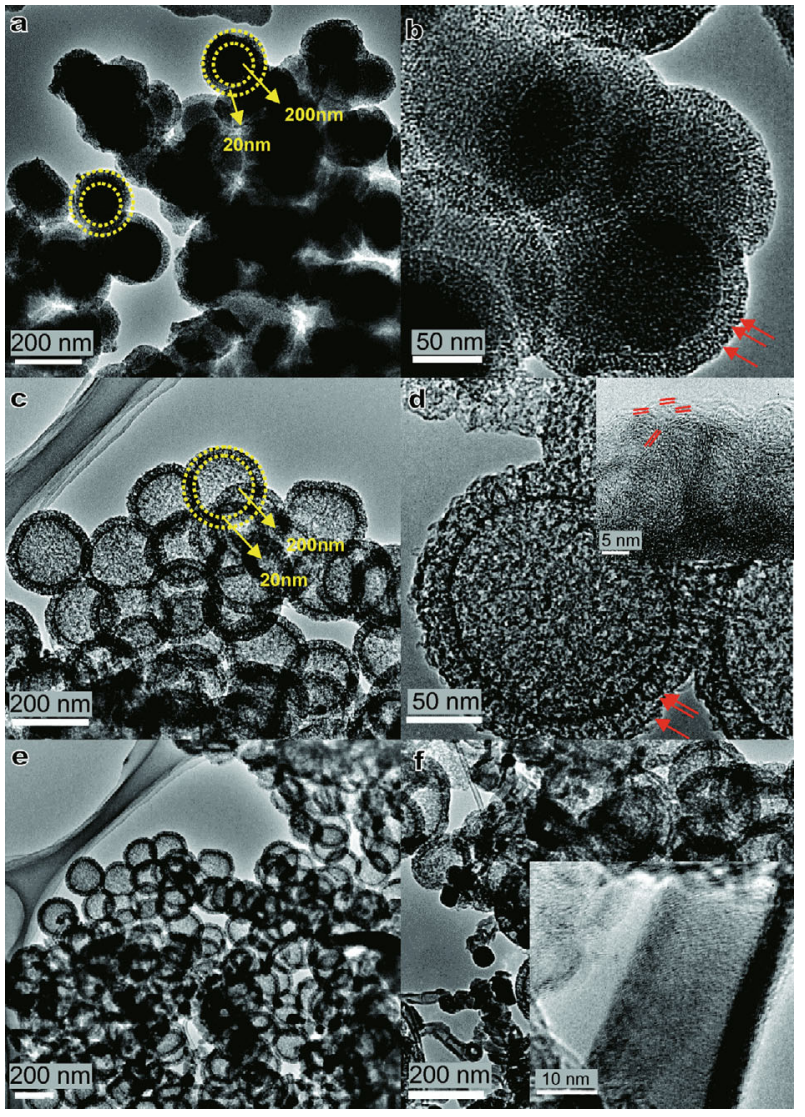

Figure 2 TEM images of $\mathrm{SiO}_{2} @ \mathrm{Fe}-\mathrm{mSiO}_{2}$ template $(\mathrm{a}, \mathrm{b})$ and $\mathrm{Fe}-\mathrm{MHCs}$ (c-f).

small Fe species was dispersed into the hard template.

TEM was also used to characterize the morphology of the Fe-MHCs. The TEM image showed that the resulting Fe-MHCs efficiently retained the spherical morphology of $\mathrm{SiO}_{2} @ \mathrm{Fe}-\mathrm{mSiO}_{2}$ with no obvious collapse observed (Fig. 2c). The TEM images clearly exhibited well monodisperse and hollow nanostructures with a shell thickness of $25 \mathrm{~nm}$ and a void in the diameter of $150 \mathrm{~nm}$, which was in agreement with the diameter of the core of template. The higher magnification TEM images of Fe-MHCs in Fig. $2 \mathrm{~d}$ showed that the sample possesses twisted disordered mesopores (the red sign), indicating Fe species has provided uniform active sites for deposition of carbon species from pyrolysis of PS in the mesopores of the template. The microstructure of these hollow spheres is a part of graphitic structure, as seen in the high resolution TEM images of the Fe-MHCs (red sign inset of Fig. 2d), which was attributed to the catalytic graphitization of the Fe species [24].

In addition, a little number of Fe nanoparticles with large size $(20-60 \mathrm{~nm})$ could be observed in the TEM 

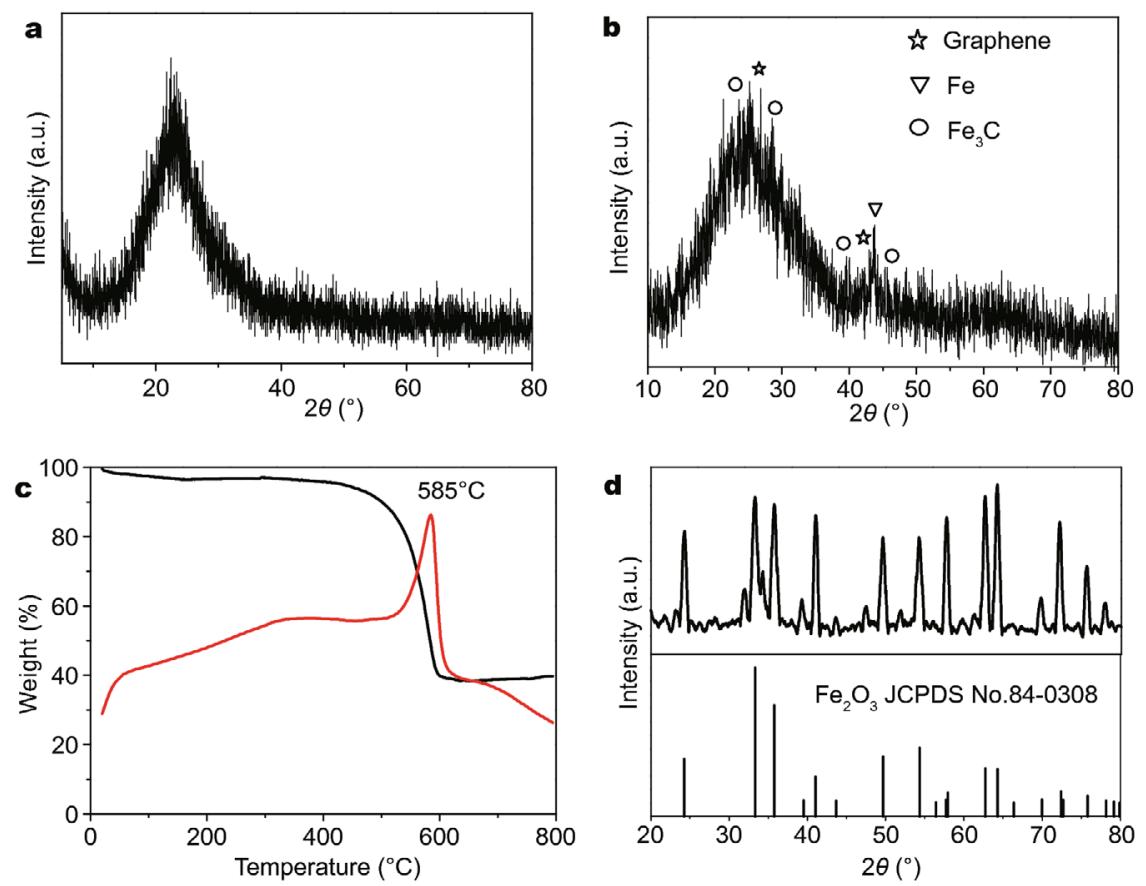

Figure 3 Wide-angle XRD patterns of $\mathrm{Fe}_{-} \mathrm{SiO}_{2} @ \mathrm{mSiO}_{2}$ (a) and Fe-MHCs (b), TGA (c) and wide-angle XRD (d) pattern of MHCs-Fe in air.

image of Fe-MHCs (Fig. 2e), which might be attributed to $\mathrm{Fe}$ aggregation at high temperature. Moreover, some carbon nanotubes (CNTs) (red circle in Fig. 2f) with the diameter of $22 \mathrm{~nm}$ also could be ascribed to the catalysis of Fe species at high temperature [25]. The high resolution TEM image (inset of Fig. 2f) of the CNTs showed that the wall was made up of more than a dozen layers of graphite. The graphitic structure could improve the material's mechanical properties and ion transport.

To establish the crystal phases of carbon and the ironbased nanoparticles, the obtained Fe-MHCs were characterized by wide angle XRD. As shown in Fig. 3a, the weak diffraction peak at $26.5^{\circ}$ could be assigned to the (002) plane of graphitic carbon [26], in agreement with TEM observation. Generally, the carbon framework with $\mathrm{Fe}^{3+}$ can turn to $\mathrm{Fe}_{3} \mathrm{C}$ at condition of pyrolysis [27]. At the same time, some $\mathrm{Fe}^{3+}$ can convert to metal of Fe [28]. Thus, the new diffraction peaks at $44.8^{\circ}$ and $65.1^{\circ}$ indicated the presence of $\alpha-F e$ (JCPDS No. 06-0696). The rest of the diffraction peaks correspond to the crystal planes of $\mathrm{Fe}_{3} \mathrm{C}$ species (JCPDS, No. 89-2867) [29,30]. The results showed that a certain amount of Fe species has been loaded in the carbon framework. To further investigate the content of $\mathrm{Fe}$ in the Fe-MHCs, the TGA in air atmosphere was performed and XRD was used to determine the type of iron after calcination. As depicted in Fig. $3 \mathrm{c}$ during the temperature from 20 to $200^{\circ} \mathrm{C}$, the mass loss was correlated to the evaporation of water. The significant mass loss occurs from 300 to $600^{\circ} \mathrm{C}$, which could be attributed to oxidation and gasification of carbon framework in the air. Carbon framework can be completely decomposed in the air and $\mathrm{Fe}_{2} \mathrm{O}_{3}$ is obtained at high temperature as seen from XRD (JCPDS No. 840308) (Fig. 3d) [31,32]. Clearly, the content of $\mathrm{Fe}_{2} \mathrm{O}_{3}$ was 39.7 wt.\% measured by TGA. The corresponding $\mathrm{Fe}$ contents was about 27.8 wt.\%.

The $\mathrm{N}_{2}$ adsorption experiments were performed to examine the pore characteristics and surface area of FeMHCs. Fig. 4a presents a type IV isotherm with a hysteresis loop at $P / P_{0}>0.4$, indicating the presence of mesopores. The BET surface area and pore volume of the composite Fe-MHCs is $924 \mathrm{~m}^{2} \mathrm{~g}^{-1}$ and $1.12 \mathrm{~cm}^{3} \mathrm{~g}^{-1}$ respectively. The higher BET surface area compared with some other hollow carbon spheres [27,33] ensures a large storage space. The Fe-MHCs possessed mesopore with size of $4.1 \mathrm{~nm}$, calculated by the conventional $\mathrm{BJH}$ method on the $\mathrm{N}_{2}$ adsorption isotherm as shown in Fig. $4 \mathrm{~b}$.

The $\mathrm{C}-\mathrm{H}$ bond oxidation is significant in the chemical industry, which could directly transform the hydrocarbons to some oxygen-containing chemicals. In general, the transition metal catalysts were usually essential in the $\mathrm{C}-\mathrm{H}$ bond oxidation. Besides, the reaction conditions such as high temperature and pressure increased the risk 

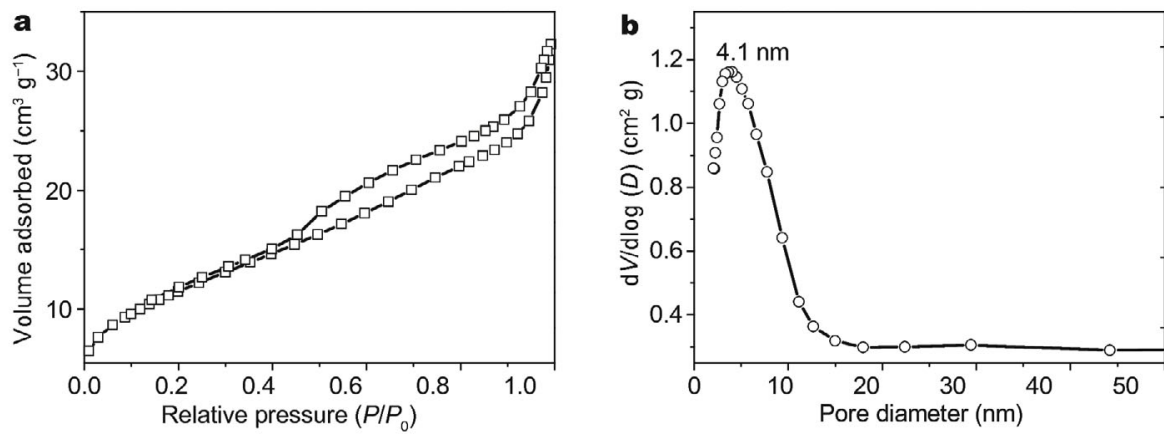

Figure 4 Nitrogen adsorption-desorption isotherms (a) and pore size distribution curves (b).

Table 1 Comparison of the catalytic results of products of Fe-MHCs with related results reported in the literature

\begin{tabular}{|c|c|c|c|c|}
\hline Catalyst & Conversion (\%) & Yield $(\%)^{\mathrm{a}}$ & Selectivity $(\%)^{\mathrm{b}}$ & Ref. \\
\hline Fe-MHCs & 94.5 & 79.3 & 97.4 & This work \\
\hline Mesoporous carbon & 88.3 & 53.4 & NA & {$[22]$} \\
\hline Active carbon & NA & 55.9 & NA & {$[8]$} \\
\hline Boron doped polymeric carbon & 10.6 & NA & 99.9 & {$[9]$} \\
\hline $\mathrm{MnCl}_{2}$ & 5 & NA & 79 & {$[10]$} \\
\hline ZJU-19 & 9 & NA & 80 & {$[10]$} \\
\hline ZJU-20 & 69 & NA & 95 & {$[10]$} \\
\hline $\mathrm{N}$-doped carbon & 94 & 80.4 & NA & [11] \\
\hline
\end{tabular}

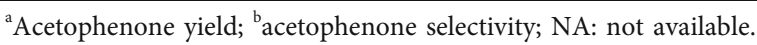

for the $\mathrm{C}-\mathrm{H}$ oxidation. So it is important to develop a new strategy for the catalytic oxidation of $\mathrm{C}-\mathrm{H}$ bonds in hydrocarbon. The carbon nanomaterials catalyse the oxidation of $\mathrm{C}-\mathrm{H}$ bonds as reported in an other works [2]. In this regard, the mesoporous hollow feature of FeMHCs can prevent the low-cost Fe nanoparticles from leaching. Inspired by those properties of Fe-MHCs, it was used as catalyst in the selective oxidation of ethylbenzene to ethylbenzene. The reaction results with Fe-MHCs as catalyst and some reported results with other catalysts were summarized in Table 1 . It was worth noting that the Fe-MHCs exhibited good catalytic performance in the selective oxidation of ethylbenzene. The conversion of ethylbenzene could reach $94.5 \%$ and the selectivity of product acetophenone was $97.4 \%$, which were better than the other results reported in some literatures [8-11,22].

In addition, the stability of Fe-MHCs catalysts was also evaluated. The conversion of ethylbenzene and selectivity to acetophenone were achieved even when the catalyst was used in the sixth run (Fig. 5). In brief, Fe-MHCs, as an efficient catalyst, exhibited excellent catalytic activity in the selective oxidation of ethylbenzene and will be a promising alternative to the traditional expensive metal and metal oxide catalysts. Moreover, the unique uniform cavity and mesoporous structures may provide a good

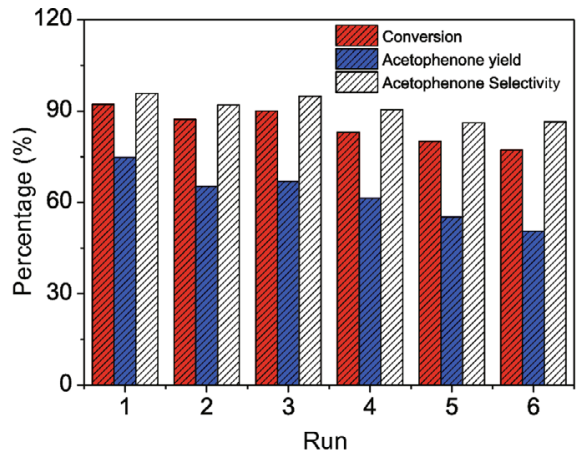

Figure 5 The stability of the MHCs-Fe catalyst.

condition for their catalytic capabilities.

\section{CONCLUSION}

In summary, we have prepared the Fe modified mesoporous hollow carbon spheres by pyrolysis and simultaneous deposition method. The Fe species and mesoporous structure of hard template were critical to deposition of carbon species from pyrolysis of PS. As catalyst, the Fe-MHCs exhibited high selectivity in the oxidation of ethylbenzene. This strategy represents an environmental-friendly and simple preparation method without high technology or complex operation. In addi- 
tion, the efficient utilization of PS as carbon precursor provides a new orientation for preparing carbon materials with controllable morphology.

Received 15 August 2017; accepted 9 October 2017; published online 28 November 2017

1 Zhang Z, Xiao F, Xi J, et al. Encapsulating Pd nanoparticles in double-shelled graphene@carbon hollow spheres for excellent chemical catalytic property. Sci Rep, 2014, 4: 4053

2 Chen Y, Shi J. Mesoporous carbon biomaterials. Sci China Mater, 2015, 58: 241-257

3 Fang X, Zang J, Wang X, et al. A multiple coating route to hollow carbon spheres with foam-like shells and their applications in supercapacitor and confined catalysis. J Mater Chem A, 2014, 2: 6191-6197

4 Chen Z, Cui ZM, Niu F, et al. Pd nanoparticles in silica hollow spheres with mesoporous walls: a nanoreactor with extremely high activity. Chem Commun, 2010, 46: 6524-6526

5 Chen X, Kierzek K, Cendrowski K, et al. CVD generated mesoporous hollow carbon spheres as supercapacitors. Colloids Surfs APhysicochem Eng Aspects, 2012, 396: 246-250

6 Chen J, Chen J, Zhang X, et al. Efficient and stable PS- $\mathrm{SO}_{3} \mathrm{H} / \mathrm{SiO}_{2}$ hollow nanospheres with tunable surface properties for acid catalyzed reactions. Appl Catal A-General, 2016, 516: 1-8

7 Bai S, Liu J, Gao J, et al. Hydrolysis controlled synthesis of aminefunctionalized hollow ethane-silica nanospheres as adsorbents for $\mathrm{CO}_{2}$ capture. Microporous Mesoporous Mater, 2012, 151: 474-480

8 Jiang Y, Liu S, Zhang Y, et al. Magnetic mesoporous nanospheres anchored with LyP-1 as an efficient pancreatic cancer probe. Biomaterials, 2017, 115: 9-18

9 Yue Q, Zhang Y, Jiang Y, et al. Nanoengineering of core-shell magnetic mesoporous microspheres with tunable surface roughness. J Am Chem Soc, 2017, 139: 4954-4961

10 Wei J, Sun Z, Luo W, et al. New insight into the synthesis of largepore ordered mesoporous materials. J Am Chem Soc, 2017, 139: 1706-1713

11 Zhu Y, Zhao Y, Ma J, et al. Mesoporous tungsten oxides with crystalline framework for highly sensitive and selective detection of foodborne pathogens. J Am Chem Soc, 2017, 139: 10365-10373

12 Li S, Pasc A, Fierro V, et al. Hollow carbon spheres, synthesis and applications - a review. J Mater Chem A, 2016, 4: 12686-12713

13 Wang Y, Zhang C, Kang S, et al. Simple synthesis of graphitic ordered mesoporous carbon supports using natural seed fat. J Mater Chem, 2011, 21: 14420-14423

14 Wei J, Ren Y, Luo W, et al. Ordered mesoporous alumina with ultra-large pores as an efficient absorbent for selective bioenrichment. Chem Mater, 2017, 29: 2211-2217

15 Ren Y, Zhou X, Luo W, et al. Amphiphilic block copolymer templated synthesis of mesoporous indium oxides with nanosheetassembled pore walls. Chem Mater, 2016, 28: 7997-8005

16 Li Y, Luo W, Qin N, et al. Highly ordered mesoporous tungsten oxides with a large pore size and crystalline framework for $\mathrm{H}_{2} \mathrm{~S}$ sensing. Angew Chem Int Ed, 2014, 53: 9035-9040

17 Zhou X, Cheng X, Zhu Y, et al. Ordered porous metal oxide semiconductors for gas sensing. Chin Chem Lett, 2017, doi: 10.1016/j.cclet.2017.06.021

18 Dai JT, Zhang Y, Li HC, et al. Enhancement of gemcitabine against pancreatic cancer by loading in mesoporous silica vesicles. Chin
Chem Lett, 2017, 28: 531-536

19 You C, Liao S, Qiao X, et al. Conversion of polystyrene foam to a high-performance doped carbon catalyst with ultrahigh surface area and hierarchical porous structures for oxygen reduction. J Mater Chem A, 2014, 2: 12240-12246

$20 \mathrm{Yu} \mathrm{L}, \mathrm{Hu} \mathrm{H}, \mathrm{Wu} \mathrm{HB}$, et al. Complex hollow nanostructures: synthesis and energy-related applications. Adv Mater, 2017, 29: 1604563

21 Zou C, Wu D, Li M, et al. Template-free fabrication of hierarchical porous carbon by constructing carbonyl crosslinking bridges between polystyrene chains. J Mater Chem, 2010, 20: 731-735

22 Chen A, Li Y, Yu Y, et al. Synthesis of hollow mesoporous carbon spheres via 'dissolution-capture' method for effective phenol adsorption. Carbon, 2016, 103: 157-162

23 Yoon SB, Kim JY, Kim JH, et al. Synthesis of monodisperse spherical silica particles with solid core and mesoporous shell: mesopore channels perpendicular to the surface. J Mater Chem, 2007, 17: 1758-1761

24 Kiciński W, Dembinska B, Norek M, et al. Heterogeneous ironcontaining carbon gels as catalysts for oxygen electroreduction: Multifunctional role of sulfur in the formation of efficient systems. Carbon, 2017, 116: 655-669

25 Fang H, Zheng J, Luo X, et al. Product tunable behavior of carbon nanotubes-supported Ni-Fe catalysts for guaiacol hydrodeoxygenation. Appl Catal A-General, 2017, 529: 20-31

26 Zhang LH, Sun Q, Liu DH, et al. Magnetic hollow carbon nanospheres for removal of chromium ions. J Mater Chem A, 2013, 1: 9477-9483

$27 \mathrm{Hu} \mathrm{Y,} \mathrm{Jensen} \mathrm{JO,} \mathrm{Zhang} \mathrm{W,} \mathrm{et} \mathrm{al.} \mathrm{Hollow} \mathrm{spheres} \mathrm{of} \mathrm{iron} \mathrm{carbide}$ nanoparticles encased in graphitic layers as oxygen reduction catalysts. Angew Chem Int Ed, 2014, 53: 3675-3679

28 Liu DH, Guo Y, Zhang LH, et al. Switchable transport strategy to deposit active $\mathrm{Fe} / \mathrm{Fe}_{3} \mathrm{C}$ cores into hollow microporous carbons for efficient chromium removal. Small, 2013, 9: 3852-3857

29 Yao T, Cui T, Wu J, et al. Preparation of acid-resistant core/shell $\mathrm{Fe}_{3} \mathrm{O}_{4} @ \mathrm{C}$ materials and their use as catalyst supports. Carbon, 2012, 50: 2287-2295

$30 \mathrm{Lu} \mathrm{AH,} \mathrm{Li} \mathrm{WC,} \mathrm{Hao} \mathrm{GP,} \mathrm{et} \mathrm{al.} \mathrm{Easy} \mathrm{synthesis} \mathrm{of} \mathrm{hollow} \mathrm{polymer,}$ carbon, and graphitized microspheres. Angew Chem Int Ed, 2010, 49: 1615-1618

31 Niu L, Liu X, Liu X, et al. In situ XRD study on promotional effect of potassium on carburization of spray-dried precipitated $\mathrm{Fe}_{2} \mathrm{O}_{3}$ catalysts. ChemCatChem, 2017, 9: 1691-1700

32 She $\mathrm{X}, \mathrm{Wu} \mathrm{J}, \mathrm{Xu} \mathrm{H}$, et al. High efficiency photocatalytic water splitting using $2 \mathrm{D} \alpha-\mathrm{Fe}_{2} \mathrm{O}_{3} / g-\mathrm{C}_{3} \mathrm{~N}_{4}$ Z-scheme catalysts. Adv Energ Mater, 2017, 7: 1700025

33 He X, Sun H, Zhu M, et al. N-doped porous graphitic carbon with multi-flaky shell hollow structure prepared using a green and 'useful' template of $\mathrm{CaCO}_{3}$ for VOC fast adsorption and small peptide enrichment. Chem Commun, 2017, 53: 3442-3445

Acknowledgements This work was supported by the National Natural Science Foundation of China (21676070), Hebei Natural Science Foundation (B2015208109), Hebei Training Program for Talent Project (A201500117), Five Platform Open Fund Projects of Hebei University of Science and Technology (2015PT37), Hebei One Hundred-Excellent Innovative Talent Program (III) (SLRC2017034) and Hebei Science and Technology Project (17214304D and 16214510D).

Author contributions Chen A and Gao Y proposed the research 
direction and guided the whole project. Du J designed and performed the experiments and wrote the manuscript; Zhang L, Zhang Y and Yu Y helped draft the manuscript and analyze the data. All authors contributed to the general discussion and reviewed the manuscript.
Conflict of interest The authors declare that they have no conflict of interest.

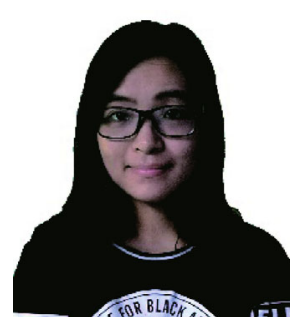

Juan Du was born in Hebei, China, in 1992. She received her BSc degree(2014) from Hebei University of Science and Technology. Up to now, she has worked on her Master thesis at Hebei University of Science and Technology, studying the synthesis and application of hollow carbon spheres and other porous carbon materials under the direction of Prof. A Chen.
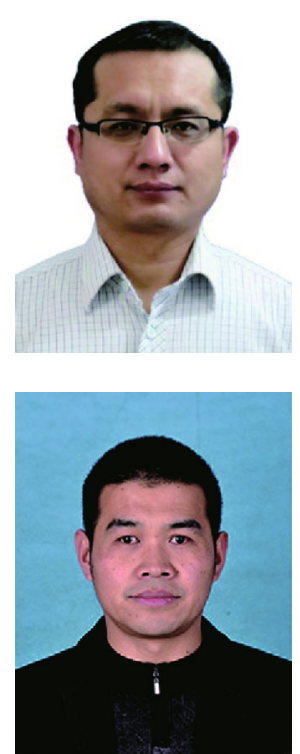

Aibing Chen received his $\mathrm{PhD}$ degree in 2007 in Dalian Institute of Chemical Physics, Chinese Academy of Sciences (China). From 2013, he is a fullprofessor at Hebei University of Science and Technology (China). His scientific interests deal with porous carbon and related materials, with the applications in catalysis, depollution, energy, $\mathrm{CO}_{2}$ capture and $\mathrm{CO}_{2}$ catalytic conversion.

Yongjun Gao is an associate professor in the College of Chemistry and Environmental Science, Hebei University, China. He was born in Hebei, China, in 1979. He earned his PhD (2012) at Dalian Institute of Chemical Physics, Chinese Academy of Sciences. Then he worked as a postdoctoral fellow in National University of Singapore for about three years and moved to Hebei University in September 2015. His main research is to develop new heterogeneous catalyst for traditional organic reactions, such as carbocatalysis, sustainable catalysis.

\section{铁修饰的中空介孔碳球用于乙苯催化氧化}

杜娟 ${ }^{1}, 弓$ 丽 $^{\text {丽 }}{ }^{1}$, 张艺馨 ${ }^{1}$, 于奕峰 ${ }^{1}$, 高勇军 ${ }^{2^{*}}$, 陈爱兵 ${ }^{{ }^{*}}$

摘要 本文通过简单的热解沉积方法成功地制备了具有大空腔和介孔壳壁的铁修饰中空碳球. 在高温碳化过程中, 聚苯乙烯分解出的小 分子有机气体(碳物种)会被介孔硅模板上的铁所捕获并沉积在模板上，从而得到铁修饰的中空介孔碳球(Fe-MHCs). 制备的Fe-MHCs 具 有均一的球形形貌, 大的比表面积 $\left(924 \mathrm{~m}^{2} \mathrm{~g}^{-1}\right)$ 和一定的铁负载量. Fe-MHCs样品中的铁及其形貌使其在乙苯氧化反应中展现了良好的催 化性能. 作为催化剂时, Fe-MHCs展现了良好的转化率(94.5\%), 高的选择性(97.4\%)以及好的循环再利用性. 